Демина М.Ф.

\title{
АДМИНИСТРАТИВНО-ПРАВОВОЕ РЕГУЛИРОВАНИЕ ЧАСТНОЙ ДЕТЕКТИВНОЙ И ОХРАННОЙ ДЕЯТЕЛЬНОСТИ И РАЗРЕШИТЕЛЬНОЙ СИСТЕМЫ
}

Аннотация: актуальность настоящей статьи обусловлена тем, что развитие института частной детективной и охранной деятельности проходит в сложной и противоречивой обстановке. Разнообразие форм собственности, развитие предпринимательской деятельности вызвали объективную необходимость формирования рынка охранных и сыскных услуг. Спрос на услуги частных детективных и охранных предприятий в настоящее время достаточно высок. По данным информационных иентров МВД России в Российской Федерации зарегистрированы свыше 23 тыс. частных охранных предприятий и около 4 тыс. служб безопасности, под охраной которых находится около 250 тыс. объектов; общая численность сотрудников частных охранных предприятий составляет 740 тыс. человек. На вооружении частных охранных предприятий находится 119 тыс. единии огнестрельного оружия, 83,7 тыс. пистолетов. На работе в частных детективных и охранных предприятиях задействовано более 1 млн чел. В прочессе исследования применялись теоретический, общефилософские методы (диалектика, системный метод, анализ, синтез, аналогия, дедукция, наблюдение, моделирование), традиционно правовые методы (формально-логический), а также методы, используемые в конкретно-социологических исследованиях (статистические, экспертные оценки и др.). В процессе построения правового государства особо остро встает вопрос о надежной защите прав и законных интересов физических и юридических лиц. В условиях рыночной экономики, существующие государственные правоохранительные органы не в полной мере обеспечивают необходимую степень безопасности субъектов предпринимательской деятельности и граждан. Этим и объясняется появление частных детективных и охранных предприятий в Российской Федерации в начале 90-х годов XX в. Ключевые слова: полиция, безопасность, охранник, детектив, сыск, МВД, ОВД, контроль, разрешение, система.

B процессе построения правового государства особо остро встает вопрос о надежной защите прав и законных интересов физических и юридических лиц. В условиях рыночной экономики, существующие государственные правоохранительные органы не в полной мере обеспечивают необходимую степень безопасности субъектов предпринимательской деятельности и граждан. Этим и объясняется появление частных детективных и охранных предприятий в Российской Федерации в начале 90-х годов XX в.

Практика стран с развитой рыночной экономикой показывает, что государственные правоох- ранительные органы не в состоянии решить все проблемы борьбы с преступностью, особенно в сфере экономки. Как отмечают западные криминологи, уголовная юстиция развалилась бы за один день, если бы ей пришлось в одиночку решать задачи борьбы с преступлениями против бизнеса ${ }^{1}$.

Государство в начале 90-х годов XX в. освободилось от части своей собственности, в связи с чем бремя обеспечения безопасности данной собствен-

См.: Дашков Г.В. Зарубежный опыт деятельности частных детективных и охранных служб // Экономическая преступность. - М., 1994. - С. 80. 
ности перешло к новым собственникам. Неизменно возрастает роль собственника, на котором лежит обязанность по принятию мер, обеспечивающих безопасность предприятий. Однако это обстоятельство не снимает ответственности с государственного гаранта безопасности всех областей жизни гражданского общества².

В настоящее время государство не обладает монопольным правом осуществлять предпринимательскую деятельность, государство также не обладает монопольным правом в сфере обеспечения безопасности предпринимательской деятельности. Во многих государствах субъектами обеспечения безопасности являются негосударственные службы безопасности, частные детективные и охранные структуры. Данные структуры сформированы и в нашей стране. Однако их формирование происходило в сложной и противоречивой социально-экономической обстановке. Изначально предприятия, осуществляющие частную детективную и охранную деятельность, возникли в нашей стране без должной правовой основы. Данное обстоятельство не могло не породить определенные осложнения в отношениях с правоохранительными органами и, прежде всего, с органами внутренних дел. В юридической литературе, посвященной рассмотрению практики деятельности российских частных детективных и охранных организаций, отмечается, что многие проблемы, связанные с осуществлением данной деятельности, объясняются тем, что до 1992 г. частная правоохранительная деятельность на территории нашей страны не регламентировалась ${ }^{3}$.

Юридический статус частная детективная и охранная деятельность в Российской Федерации, получила после принятия Закона РФ от 11 марта 1992 г. «0 частной детективной и охранной деятельности в Российской Федерации» ${ }^{4}$ В данном

\footnotetext{
2 См.: Вандышев В.В. Обеспечение безопасности предприятий в условиях рыночных отношений // Экономическая преступность. - М., 1994. - С. 83.

3 См.: Выхристюк О.В. Проблемы частной детективной деятельности // Следователь. - 1998. - № 7. - С. 54; Амельчаков И.Ф., Белорусов В.Б. Частная детективная и охранная деятельность в России. - М., 2003. - С. 60; Конюшкина Ю.А. Проблемы законодательства о частной детективной деятельности в Российской Федерации // Юрист. - 2003. - № 9. - С. 13; Антипов В.Г. Виды и квалификация некоторых административных правонарушений в сфере оборота гражданского и служебного оружия, а также в сфере частной детективной и охранной деятельности. - Домодедово, 2005. - С. 18 и др.

4 См.: Ведомости Съезда народных депутатов и Верховного Совета РФ. - 1992. — № 17. - Ст. 888.
}

законе частная детективная и охранная деятельность определяется как оказание на возмездной договорной основе услуг физическим и юридическим лицам предприятиями, имеющими специальное разрешение (лицензию) органов внутренних дел, в целях защиты законных прав и интересов своих клиентов (ст. 1).

В научной литературе, где исследуются проблемы частной детективной и охранной деятельности, данная деятельность определяется далеко не однозначно. В настоящее время существуют определенные сложности в исследовании рассматриваемого феномена, поскольку понятие, которое вкладывается в содержание частной детективной и охранной деятельности, в юридической литературе понимается неоднозначно, так как один и тот же термин несет разную смысловую нагрузку в зависимости от ряда факторов (специфики работы, особенностей авторского подхода к проблеме и т.д.). Вместе с тем в любой отрасли науки происходят по мере углубления и расширения знаний уточнения понятий и определений, и, следовательно, идет пересмотр устоявшейся терминологии: «нельзя забывать важнейших требований, предъявляемых к научной терминологии, - eе однозначности, строгой определенности, ясности, устойчивости, совместимости со всем комплексом употребляемых в науке терминов. Обогащение понятийного аппарата науки должно происходить не за счет утраты точности терминов, так как утрачивается скоординированность научных понятий» ${ }^{5}$.

Вышесказанное имеет самое непосредственное отношение и к теме настоящего исследования.

Как уже отмечалось, проблема гражданскоправового и административно-правового регулирования частной детективной и охранной деятельности была предметом научного анализа. В этой связи в научной литературе исследуемому феномену уже даны определения ${ }^{6}$.

\footnotetext{
5 Алексеев С.С. Общая теория права. Т. І. — M., 1981. - С. $35-36$.

6 См.: Бровкин А.В. Договор на оказание частных детективных (сыскных) услуг: Автореф. дис. ... канд. юрид. наук. М., 1998; Белорусов В.Б. Проблемы совершенствования административно-правового регулирования частной детективной и охранной деятельности: Автореф. дис. ... канд. юрид. наук. - Саратов, 2000; Брагер Д.К. Административноправовая организация частной детективной и охранной деятельности: Автореф. дис. ... канд. юрид. наук. - Хабаровск, 2002; Иванов П.В. Частная детективная и охранная деятельность (административно-правовой аспект): Автореф. дис. ... канд. юрид. наук. - СПб., 1998; Солнышкова О.В. Государ-
} 
В частности, В.И. Козлов отмечает, что частная детективная и охранная деятельность - это деятельность по защите прав и законных интересов физических и юридических лиц, а также по оказанию им иных услуг специально созданными для этих целей негосударственными предприятиями, действующими на договорной возмездной основе, использующими специальные силы, средства и методы в соответствии с законом и при неуклонном соблюдении установленного порядка ${ }^{7}$.

А.Ю. Шумилов определяет частную сыскную деятельность как основанную на законе и облеченную в правовую форму правовых отношений деятельность негосударственных субъектов (частных сыщиков и организаций), использующих специальные силы и средства, осуществляемую посредством оказания услуг в сфере уголовного и гражданского судопроизводства ${ }^{8}$.

А.В. Агутин под частной детективной деятельностью понимает совокупность действий индивидов и их объединений, имеющих специальное разрешение, по оказанию услуг физическим и юридическим лицам за вознаграждение, с целью защиты их частной собственности или иного законного интереса ${ }^{9}$.

В.Г. Семенов частную детективную и охранную деятельность определяет как предусмотренную законом и полагает, что это - определенный вид юридической, лицензируемой деятельности по оказанию услуг юридическим и физическим лицам на возмездной договорной основе в целях защиты их прав и законных интересов ${ }^{10}$.

В.Б. Белорусов рассматривает частную детективную и охранную деятельность как регулируе-

ственное регулирование негосударственной (частной) детективной и охраной деятельности в Российской Федерации: Автореф. дис. ... канд. юрид. наук. - Тюмень, 2001; Федорова О.Г. Гражданско-правовое регулирование частной детективной и охранной деятельности в Российской Федерации: Дис. ... канд. юрид. наук. - СПб., 2002.

7 См.: Козлов В.И. Административно-правовое регулирование частной детективной и охранной деятельности в Российской Федерации: Дис. ... канд. юрид. наук. - М., 1999. C. 16.

8 См.: Шумилов А.Ю. Частное детективное и охранное право. - М., 1999. - С. 21.

9 См.: Агутин А.В. Правовые и тактические аспекты частной сыскной и охранной деятельности: Дис. ... канд. юрид. наук. - Н. Новгород, 1996. - С. 46.

10 См.: Семенов В.Г. Частная детективная деятельность при расследовании преступлений. - М., 2006. - С. 20. мую преимущественно нормами административного права, как один из методов правоохранительной деятельности, состоящий в оказании гражданам и организациям со стороны частных детективов охранных и охранно-сыскных услуг, имеющих публичный характер, и осуществляемый в целях защиты законных прав и интересов граждан и организаций на основе специального государственного разрешения ${ }^{11}$.

Необходимо сказать, что определение частной детективной и охранной деятельности дает возможность отождествлять ее с правоохранительной деятельностью, однако данная деятельность отличается от правоохранительной деятельности по ряду признаков:

- $\quad$ по своему характеру частная детективная и охранная деятельность осуществляется в рамках административно-правового и гражданскоправового режима и направлена на получение прибыли;

- $\quad$ частная детективная и охранная деятельность носит целенаправленный характер;

- $\quad$ частная детективная и охранная деятельность базируется на договорных отношениях, где четко определены пределы и время возникновения и прекращения этих отношений;

- $\quad$ частная детективная и охранная деятельность осуществляется в установленных законом формах и с помощью специально определенных методов;

- $\quad$ лица, осуществляющие частную сыскную деятельность, не наделены полномочиями должностных лиц правоохранительных органов;

- $\quad$ частная детективная и охранная деятельность преимущественно носит предупредительный характер.

Компетенция данных частых детективных и охранных структур заканчивается (переходит к государственным правоохранительным органам) в случае совершения преступных действий в отношении клиента.

Вышеизложенное дает возможность сформулировать следующее определение частной детективной и охранной деятельности.

Частная детективная и охранная деятельность это деятельность, которая осуществляется в рамках административно-правового и гражданско-пра-

11 См.: Белорусов В.Б. Административно-правовой статус негосударственных субъектов правоохранительной деятельности в Российской Федерации: Автореф. дис. ... д-ра юрид. наук. - М., 2005. - С. 32. 
вового режима, в установленных законом формах и с помощью специально определенных методов, направленных на обеспечение защиты прав и законных интересов физических и юридических лии, с которыми заключен соответствующий договор.

Сформулированное определение дает возможность увидеть, что институт частной детективной и охранной деятельности носит двойственную природу: в данном институте сочетаются как публичноправовые, так и частно-правовые начала. Договор на оказание услуг частно-детективного или охранного характера является юридическим фактом для осуществления соответствующей деятельности. Несмотря на то, что в конечном итоге частная детективная и охранная деятельность направлена на получение прибыли, данная деятельность не является предпринимательской деятельностью. Частная детективная и охранная деятельность по своему содержанию и по своей цели носит административно-правовой характер, проявляет себя в установленных формах и осуществляется в рамках разрешительной системы. Хотя институт разрешительной системы за последние годы претерпел кардинальные изменения, тем не менее, представить себе безопасность и правопорядок в сфере осуществления публичного управления без регулятивных и охранительных аспектов разрешительной системы не возможно. И коль скоро частная детективная и охранная деятельность подпадает под режим разрешительной системы, есть смысл кратко рассмотреть, что понимается под данным институтом в науке административного права.

В.А. Власов, С.С. Студеникин в своем учебнике отмечают, что разрешительная система представляет собой совокупность актов соответствующих органов государственной власти, регулирующих порядок производства (изготовления, открытия), приобретения (пользования, хранения), сбыта ношения и перевозки строго определенных предметов и веществ (оружия, боеприпасов, взрывчатых веществ, ядов и др.), а также порядок въезда и временного проживания лиц в запретной пограничной зоне, пограничной полосе и отдельных местностях. Отличительной особенностью разрешительной системы является обязательность получения разрешения от соответствующих государственных органов, а основное назначение ее - охрана государственного порядка, общественной и личной безопасности граждан от всех преступных посягательств ${ }^{12}$.

12 См.: Власов В.А., Студеникин С.С. Советское административное право. - М., 1959. - С. 276.
В частности, Г.Г. Месхи говорит о том, что разрешительная система - это регулируемая нормами права совокупность общественных отношений, складывающихся в процессе обеспечения установленного порядка изготовления, приобретения, хранения, перевозки, использования и уничтожения строго определенных технических устройств, специальных изделий и физико-химических веществ (в том числе оружия, боеприпасов, взрывчатых материалов, сильнодействующих ядовитых, наркотических и радиоактивных веществ, множительной техники и штемпельно-граверных изделий), нарушение которых может нанести ущерб общественным и государственным интересам ${ }^{13}$.

М.И. Еропкин определяет разрешительную систему как совокупность правил, регламентирующих порядок производства, приобретения, пользования, хранения, сбыта и перевозки некоторых предметов и веществ, а также порядок открытия и функционирования некоторых предприятий ${ }^{14}$.

Таким образом, разрешительная система является неотъемлемым элементом в механизме обеспечения общественной безопасности. Как отмечает Б.П. Кондрашов, сущность лицензионноразрешительной системы - обеспечение безопасности личности, общества и государства ${ }^{15}$.

Разрешительная система в сфере внутренних дел дает возможность обеспечить не только безопасность личности, общества и государства, но также позволяет гражданам и юридическим лицам легитимно реализовать ряд своих гражданских прав.

Д.Н. Бахрах и Д.В. Осинцев определяют разрешительную систему как самостоятельный правовой институт в структуре административного права, опосредующий взаимоотношения граждан (юридических лиц) и аппарата исполнительной власти, возникающие по поводу предоставления первым социального правового статуса, позволяющего заниматься определенными видами небезопасной деятельности ${ }^{16}$.

13 См.: Месхи Г.Г. Организация и тактика осуществления разрешительной системы органами внутренних дел: Автореф. дис. ... канд. юрид. наук. - М., 1982. - С. 12.

14 См.: Еропкин М.И. Управление в области охраны общественного порядка. - М., 1965. - С. 107.

15 См.: Кондрашов Б.П. Общественная безопасность и административно-правовые средства ее обеспечения. - М., 1998. - C. 130.

16 См.: Бахрах Д.Н., Осинцев Д.В. Правовой режим разрешительной системы // Правовая реформа и реформа юридического образования. - Воронеж, 1995. - С. 11. 
И.Ф. Амельчаков, В.Б. Белорусов разрешительную систему определяют как установленный и регламентированный правом порядок, комплекс административно-правовых норм и правил, регулирующих производство, приобретение, пользование, хранение, сбыт и перевозку определенных предметов и веществ, функционирование отдельных предприятий, а также совершение предусмотренных разрешением действий ${ }^{17}$.

По мнению П.В. Иванова разрешительная система - это совокупность административно-правовых норм, регламентирующих порядок ведения гражданами (имеющих лицензию) детективной и охранной деятельности, порядок оборота оружия, боеприпасов, взрывчатых веществ, соблюдения правил открытия и функционирования лицензированных охранно-сыскных предприятий с особыми уставными задачами, а также предприятий и организаций, производящих и реализующих оружия (предметы), в целях охраны общественного порядка и обеспечения общественной безопасности ${ }^{18}$.

Н.М. Жаворонков, исследуя сущность данной системы, говорит о том, что «разрешительная система, осуществляемая органами внутренних дел, - это закрепленный в административноправовых нормах порядок производства, приобретения, использования, хранения, перевозки строго определенных предметов и веществ, а также особый порядок открытия и функционирования некоторых предприятий и организаций ${ }^{19}$. По мнению Н.М. Жаворонкова разрешительная система установлена в отношении предметов и веществ, бесконтрольное пользование которыми может нанести вред государству или личной безопасности граждан.

Таким образом, разрешительная система распространяется на огнестрельное нарезное и холодное оружие, боеприпасы к огнестрельному нарезному оружию, взрывчатые материалы, сильнодействующие, ядовитые и радиоактивные вещества, метанол, охотничий порох, оружейно-ремонтные, пиротехнические мастерские,

\footnotetext{
17 См.: Амельчаков И.Ф., Белорусов В.Б. Лицензионно-разрешительная деятельность органов внутренних дел. - Тамбов, 2003. - С. 5.

18 См.: Иванов П.В. Частная детективная и охранная деятельность (административно-правовой аспект): Автореф. дис. ... канд. юрид. наук. - СПб., 1998. - С. 16.

19 Жаворонков Н.М. Осуществление разрешительной системы. - М., 1973. - С. 3.
}

предприятия по производству огнестрельного оружия, стрелковые тиры, магазины, торгующие нарезным и охотничьим оружием, а также боеприпасами. Как уже было сказано, разрешительная система распространяется и на предприятия, осуществляющие частную детективную и охранную деятельность.

Следует сказать, что значение разрешительной системы будет в перспективе только возрастать, поэтому необходимо законодательно закрепить основы и принципы реализации и обеспечения разрешительной системы в специальном Законе «Об основах разрешительной системы в Российской Федерации». Институт разрешительной системы может быть определен как комплекс правовых норм, определяющих порядок осуществления деятельности, связанной с предоставлением работ, услуг, представляющих повышенную общественную опасность.

Далее целесообразно обратиться к истории анализируемого вопроса, поскольку без определения тенденций развития института частной детективной и охранной деятельности настоящее исследование будет неполным.

История показывает, что совершенствование законодательства о частной детективной и охранной деятельности, начатое в настоящее время, во многом аналогично тем процессам, которые имели место в нашей стране с середине XIX в. «Исторический метод исследования предполагает рассмотрение существующих государственно-правовых явлений не только под углом зрения их настоящего, но и с позиций их прошлого и будущего. Современные правовые реалии во многом определяются правовым прошлым. В свою очередь правовые реалии сегодняшнего дня в значительной степени предопределяют завтрашний день права. Таким образом, историко-правовой метод позволяет ответить на вопросы, касающиеся причин возникновения того или иного государственно-правового явления, условий их развития в прошлом и настоящем, основных перспектив и тенденций их эволюции в будущем» ${ }^{20}$.

Трудно согласиться с существующим утверждением, что частная детективная и охранная деятельность в России - явление принципиально новое в отечественной правоохранительной прак-

20 Ялбулганов А.А. Зарождение государственного контроля в России во второй половине XVII-XVIII вв. (историкоправовое исследование) // Государство и право. - 2001. - № 10. - C. 89. 
тике и не имеет истории и традиций ${ }^{21}$. Данное утверждение не совсем точное, так как не в полной мере учитывает имеющиеся материалы по истории развития частного сыска и охраны в Российской империи.

Исследование показывает, что зарождение частного сыска и охраны в нашей стране происходило гораздо раньше, чем в зарубежных государствах (Франции, США, Японии, Германии и др.): «одной из существенных экономических причин развития частных детективных и охранных структур в США явилось стремление предпринимателей в условиях обострения конкурентной борьбы на многих товарных рынках и в сфере банковскостраховых услуг максимально сохранить конфиденциальность своих коммерческих операций ${ }^{22}$.

Но появление частно-сыскной деятельности как самостоятельного административно-правового института произошло гораздо позднее, чем в названных зарубежных государствах, поскольку не было экономических и социальных предпосылок развития частной детективной и охранной деятельности.

В то же время исторические документы свидетельствуют о том, что структура полиции России конца XIX - начала XX вв., исходя из источников финансирования и выполняемых функций, подразделялась на:

- государственную;

- ведомственную;

- $\quad$ частную.

Государственная полиция была основана в первой четверти XVIII в. и выполняла, наряду с чисто правоохранительными функциями, общеадминистративные полномочия, такие как сыск беглых крестьян, мастеровых, солдат; осуществляла борьбу с бродяжничеством и попрошайничеством, паспортный режим и контроль, дознания по уголовным делам и др ${ }^{23}$.

В 30-е годы XVIII в. создается ведомственная полиция. В 1734 г. в Екатеринбурге для управления горнозаводским населением была создана горнозаводская полиция. Однако в последующем, в 1789

21 См.: Арестова Е.Н. Организационно-правовые и социологические аспекты взаимодействия органов внутренних дел с частными детективными и охранными службами: Автореф. дис. ... канд. юрид. наук. - М., 1995. - С. 3.

22 См.: Крысин А.В. Безопасность предпринимательской деятельности. - М., 1996. - С. 26.

23 См.: Курицын В.М. История полиции дореволюционной России. - М., 1981. - С. 23. г., она была объединена с созданной городской полицией. Тем не менее, впоследствии на основании закона от 1870 г. можно говорить о возрождении ведомственной полиции: на золотых приисках было учреждено несколько должностей особых исправников, содержащихся за счет ведомств (промышленных и акционерных компаний), но подчиненных губернаторам.

Необходимо отметить, что история развития полиции Российской империи свидетельствует о том, что в организации полицейского управления на местах не было единства и последовательности, что во многом определялось политическими мотивами. Структура полиции неоднократно подвергалась реформированию.

Горно-полицейская стража, как прообраз ведомственной полиции и существовавшей ранее горнозаводской полиции, была вновь образована 8 мая 1900 г. на золотых и платиновых приисках Урала и содержалась за счет казны и золотопромышленников ${ }^{24}$.

Служба горно-полицейской стражи строилась в соответствии с инструкциями, которые утверждались МВД отдельно для каждой губернии ${ }^{25}$. К концу XIX в. полиция была малочисленна, ее размещение не соответствовало плотности населения. Полиция рассматривалась по-прежнему как учреждение городское. Хотя именно на периферии, в сельской местности, увеличивалось социальное напряжение. В этой связи увеличилось число ходатайств частных лиц к правительству об учреждении полицейских должностей на территориях на свои собственные средства.

Впервые в Российской империи частная полиция была создана Кабинетом министров 2 июня 1872 г. в соответствии с Высочайше утвержденным положением на заводе «Новороссийского общества каменно-угольного, рельсового и железнодорожного производства» в составе 15 полицейских и полицейского надзирателя.

Однако на законодательном уровне образование частной полиции стало регламентироваться только в начале XX в., на основании Высочайшего указа от 12 мая 1900 г. «0 предоставлении министру внутренних дел права разрешать ходатайства

24 См.: Полное собрание законодательства Российской империи. Собр. 3. Т. 20. Отд. 2. № 18547.

25 См.: Инструкция горно-полицейским урядникам и стражникам Иркутской губернии: Утверждена МВД 6 июня 1902 г. // Собрание узаконениий и распоряжений правительства. - М., 1902. - Ст. 10. 
общественных учреждений и частных обществ и лиц об учреждении должностей пеших и конных полицейских стражников во всех губерниях европейской и азиатской России» ${ }^{26}$.

Названным нормативным правовым актом, а также «Правилами об образовании обществами и частными лицами должностей полицейских чиновников и команд полицейской стражи» были сняты все территориальные ограничения на развитие частной полиции на территории Российской империи и установлен круг субъектов, по инициативе и на средства которых создавалась частная полиция.

Таким образом, в Российской империи наряду с государственной и ведомственной полицией существовала и полиция частная. От государственной и ведомственной полиции частная полиция отличалась рядом признаков:

- содержалась за счет негосударственных источников финансирования, обеспечивалась юридическими лицами (промышленными и акционерными компаниями и др.);

- как учреждаемая министром внутренних дел на основании ходатайств учреждений (юридических лиц), прежде всего, обеспечивала защиту их имущественных интересов, то есть, употребляя современную терминологию, интересов своих клиентов.

Приведенные факты дают возможность констатировать, что институт оказания частных охранных услуг в сфере предпринимательства имеет свою историю развития на территории нашей страны и не является принципиально новым для нашей правовой системы.

После октября 1917 г. функции по оказанию охранных услуг в части охраны государственных учреждений и организаций различных форм собственности, перешли к советскому государству. Поскольку, в соответствии с нормативными ак- тами, одной из главных задач правоохранительных структур советского государства являлась охрана национализированных предприятий и иных объектов государственной собственности, то экономические и социальные предпосылки существования частных полицейских подразделений перестали существовать. Однако административно-правовые основы частной детективной и охранной деятельности, а также вопросы о возможности использования негосударственных структур в правоохранительной деятельности отчасти были уже предметом исследования российских административистов ${ }^{27}$. Необходимо сказать, что в 1922 г. был подготовлен проект Декрета Совнаркома Российской Федерации о частной сыскной и охранной деятельности. Бывший в то время начальником Уголовного розыска республики Кацнельсон указывал: «Работа сыскных бюро по негласному наблюдению и осведомлению должна в значительной мере разгрузить работу в этой области активных сотрудников уголовного розыска, не могущих по своей малочисленности достаточно успешно бороться с громадною преступностью в крупнейших городах РСФСР» ${ }^{28}$.

В 20-годы XX в. одной из важнейших задач частных сыскных бюро представлялась помощь правоохранительным органам в предупреждении и раскрытии преступлений. Частные сыскные бюро рассматривались как дополнение к малочисленному штату уголовного розыска.

В настоящее время Правовую основу частной детективной и охранной деятельности в России составляют: Конституция Российской Федерации, устанавливающая основополагающие начала правоотношений в сфере обеспечения безопасности, Кодекс Российской Федерации об административных правонарушениях, Уголовный кодекс РФ, Гражданский кодекс РФ, Налоговый кодекс РФ.

\section{Библиография:}

1. Арестова Е.Н. Организационно-правовые и социологические аспекты взаимодействия органов внутренних дел с частными детективными и охранными службами: Автореф. дис. ... канд. юрид. наук. M., 1995. - C. 3.

2. Амельчаков И.Ф., Белорусов В.Б. Частная детективная и охранная деятельность в России. - М., 2003.

3. Вандышев В.В. Обеспечение безопасности предприятий в условиях рыночных отношений // Экономическая преступность. - М., 1994.

4. Выхристюк О.В. Проблемы частной детективной деятельности // Следователь. - 1998. - № 7.

26 См.: Полное собрание законодательства Российской империи. Собр. 3. Т. ХХ. Отд. 1. № 18599.

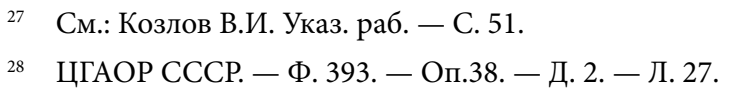


5. Дашков Г.В. Зарубежный опыт деятельности частных детективных и охранных служб // Экономическая преступность. - М., 1994.

6. Крысин А.В. Безопасность предпринимательской деятельности. - М., 1996.

7. Курицын В.М. История полиции дореволюционной России. - М., 1981.

8. Костенников М.В., Куракин А.В. Актуальные проблемы административного права. - М., 2013.

9. М.Ф. Дёмина Административно-юрисдикционная и контрольная деятельность в сфере осуществления час тной детективной и охранной деятельности // Административное и муниципальное право. 2011. - 12. - С. 64-68.

10. Демина М.Ф. К вопросу о понятии частной детективной и охранной деятельности в административном праве // Административное и муниципальное право. - 2011. - 11. - С. 29-32.

11. Куракин А.В., Костенников М.В. Административно-правовое противодействие коррупции в системе государственной службы и в деятельности сотрудников полиции Российской Федерации и зарубежных государств // NB: Российское полицейское право. - 2013. - 1. - C. 65-83. URL: http://www.enotabene.ru/pm/article_735.html

12. Костенников М.В., Трофимов О.Е. Правовое регулирование транспортной безопасности и роль полиции в ее обеспечении // NB: Административное право и практика администрирования. - 2013. - 9. C. 18-52. URL: http://www.e-notabene.ru/al/article_10134.html

13. Костенников М.В., Куракин А.В. Административно-правовое противодействие коррупции в системе государственной службы и в деятельности сотрудников полиции Российской Федерации и зарубежных государств. // Полицейская деятельность. - 2011. - 1. - С. 10-16.

\section{References (transliterated):}

1. Arestova E.N. Organizatsionno-pravovye i sotsiologicheskie aspekty vzaimodeistviya organov vnutrennikh del s chastnymi detektivnymi i okhrannymi sluzhbami: Avtoref. dis. ... kand. yurid. nauk. - M., 1995. - S. 3.

2. Amel'chakov I.F., Belorusov V.B. Chastnaya detektivnaya i okhrannaya deyatel'nost' v Rossii. - M., 2003.

3. Vandyshev V.V. Obespechenie bezopasnosti predpriyatii v usloviyakh rynochnykh otnoshenii // Ekonomicheskaya prestupnost'. - M., 1994.

4. Vykhristyuk O.V. Problemy chastnoi detektivnoi deyatel'nosti // Sledovatel'. — 1998. — № 7.

5. Dashkov G.V. Zarubezhnyi opyt deyatel'nosti chastnykh detektivnykh i okhrannykh sluzhb // Ekonomicheskaya prestupnost'. - M., 1994.

6. Krysin A.V. Bezopasnost' predprinimatel'skoi deyatel'nosti. — M., 1996.

7. Kuritsyn V.M. Istoriya politsii dorevolyutsionnoi Rossii. - M., 1981.

8. Kostennikov M.V., Kurakin A.V. Aktual'nye problemy administrativnogo prava. - M., 2013.

9. M.F. Demina Administrativno-yurisdiktsionnaya i kontrol'naya deyatel'nost' v sfere osushchestvleniya chas tnoi detektivnoi i okhrannoi deyatel'nosti // Administrativnoe i munitsipal'noe pravo. - 2011. - 12. — C. 64-68.

10. Demina M.F. K voprosu o ponyatii chastnoi detektivnoi i okhrannoi deyatel'nosti v administrativnom prave // Administrativnoe i munitsipal'noe pravo. - 2011. - 11. - C. 29-32.

11. Kurakin A.V., Kostennikov M.V. Administrativno-pravovoe protivodeistvie korruptsii v sisteme gosudarstvennoi sluzhby i v deyatel'nosti sotrudnikov politsii Rossiiskoi Federatsii i zarubezhnykh gosudarstv // NB: Rossiiskoe politseiskoe pravo. - 2013. - 1. - C. 65-83. URL: http://www.e-notabene.ru/pm/article_735.html

12. Kostennikov M.V., Trofimov O.E. Pravovoe regulirovanie transportnoi bezopasnosti i rol' politsii v ee obespechenii // NB: Administrativnoe pravo i praktika administrirovaniya. - 2013. - 9. - C. 18-52. URL: http://www.e-notabene.ru/al/article_10134.html

13. Kostennikov M.V., Kurakin A.V. Administrativno-pravovoe protivodeistvie korruptsii v sisteme gosudarstvennoi sluzhby i v deyatel'nosti sotrudnikov politsii Rossiiskoi Federatsii i zarubezhnykh gosudarstv. // Politseiskaya deyatel'nost'. - 2011. - 1. - C. 10-16. 